\title{
Efficacy of Root Canal Instrumentation and Fracture Strength Assessment in Primary Molars after Preparing Two Different Shapes of Access Cavity: An Ex Vivo Histological Study
}

\author{
Yashika Singhal $^{1}$, Nikhil Srivastava ${ }^{2}$, Vivek Rana ${ }^{3}$, Noopur Kaushik $^{4}$, Vandana Reddy ${ }^{5}$
}

\begin{abstract}
Aim and objective: To evaluate the efficacy of root canal instrumentation and fracture strength assessment in primary molars after preparing different shapes of access cavity design.

Materials and methods: Sixty extracted primary mandibular molars with at least 2/3rd roots were randomly, equally divided into two groups based on shapes of the access cavities; Group I: Traditional access cavity (TAC), Group II: Conservative access cavity (CAC). Each group was further subdivided into two subgroups with 15 samples each. After, root canal debridement, samples in subgroup 1 were sectioned for histological evaluation of root canal instrumentation efficacy, while subgroup 2 were assessed for fracture strength using a Universal Testing Machine. The data were analyzed statistically using Mann-Whitney and post hoc Tukey tests, with a $p$ value $<0.05$.

Results: Traditional access cavity showed statistically significant root canal debridement efficacy $(p<0.05)$ compared with CAC. Statistically significant differences were obtained between fracture strength values among the two groups $(p<0.05)$, with considerably higher fracture strength in the CAC group than TAC.

Conclusion: Traditional access cavity design resulted in complete root canal debridement but caused weakening of tooth structure due to low fracture strength, necessitating the use of full coverage restoration postendodontic therapy.

Keywords: Access cavity, Fracture strength, Pediatric endodontics, Primary tooth, Root canal debridement, Root canal instrumentation.

International Journal of Clinical Pediatric Dentistry (2021): 10.5005/jp-journals-10005-1997
\end{abstract}

\section{INTRODUCTION}

Primary teeth are valuable assets in the overall growth and development of a child. Besides, being the best space maintainer, primary teeth safeguard esthetics and mastication, speech aids, prevents aberrant tongue habits and psychological effects that may be associated with loss of teeth. Therefore, prevention and treatment of pulp and periapical diseases in the primary and immature permanent dentition remain a prime concern of pediatric dental practice. ${ }^{1}$ Endodontic therapy in primary dentition is the reasonable treatment option rather than the extraction as it ensures long-time survival and physiological exfoliation of primary tooth or eruption of underlying permanent tooth. ${ }^{1}$ Pulpectomy can be performed in primary teeth with pulpal insult due to caries, mechanical or chemical or thermal trauma, pulpal necrotic furcation involvement with the loss of bone or external root resorption, etc. However, endodontic treatment in primary dentition is complicated, due to the complex anatomy, tortuous nature of the root canal system, and continually occurring morphological changes. The overall success rate of pulpectomy in primary molars has been estimated to be $77.7 \%$. $^{2}$ The success of pulpectomy largely depends on appropriate access cavity preparation, chemomechanical preparation, and disinfection of root canals and obturating the canal space with suitable inert material, followed by full coverage restoration. ${ }^{3}$ Access cavity preparation is the first and one of the important steps in endodontic therapy. The objectives of access cavity preparation include removal of all caries, conservation of sound tooth structure, deroofing the pulp chamber completely, removal of all coronal pulp tissue (vital or necrotic), location of all root canal orifices, and achieving straight-line access to the
${ }^{1-5}$ Department of Pediatric and Preventive Dentistry, Subharti Dental College and Hospital, Meerut, Uttar Pradesh, India

Corresponding Author: Yashika Singhal, Department of Pediatric and Preventive Dentistry, Subharti Dental College and Hospital, Meerut, Uttar Pradesh, India, Phone: +91 7534994105, e-mail: yashikasinghal2012@gmail.com

How to cite this article: Singhal Y, Srivastava N, Rana V, et al. Efficacy of Root Canal Instrumentation and Fracture Strength Assessment in Primary Molars after Preparing Two Different Shapes of Access Cavity: An Ex Vivo Histological Study. Int J Clin Pediatr Dent 2021;14(4):518-524. Source of support: Nil

Conflict of interest: None

apical foramen. ${ }^{4}$ Improper access cavity preparation leads to procedural errors and complications such as difficulty in orifice location, incomplete removal of pulp and debris, missed extra canals and perforation, etc. ${ }^{4}$ The shape of access cavity preparation in primary teeth is considered to be similar or a miniature design of its simulated counterpart in permanent dentition. ${ }^{4,5}$

Traditional access cavity (TAC) design remained unchanged for decades with only minor modifications. ${ }^{4}$ In primary molars, TAC involves gross removal of tooth structure beyond gaining access to canal orifices to facilitate extirpation of pulp, cleaning, shaping, and filling of root canals. In TAC, straight-line access provides the best chance of debridement of the entire canal space; reducing the risk of instrument separation ${ }^{6}$ and facilitates straight entry into the canal orifice. However, this usually results in extensive loss of hard

(c) The Author(s). 2021 Open Access This article is distributed under the terms of the Creative Commons Attribution 4.0 International License (https://creativecommons. org/licenses/by-nc/4.0/), which permits unrestricted use, distribution, and non-commercial reproduction in any medium, provided you give appropriate credit to the original author(s) and the source, provide a link to the Creative Commons license, and indicate if changes were made. The Creative Commons Public Domain Dedication waiver (http://creativecommons.org/publicdomain/zero/1.0/) applies to the data made available in this article, unless otherwise stated. 
tissue that weakens the rigidity of a tooth and decreases its fracture resistance. ${ }^{7}$ Loss of tooth structure has been considered as the main cause of failure in endodontically treated teeth. Traditional access cavity preparation is considered to be the second-largest cause of failure of endodontic treatment. ${ }^{8}$ Thus, a modified access cavity design could enhance the outcome of root canal treatment. ${ }^{9}$

The conservative access cavity (CAC) preparation ${ }^{10,11}$ is another approach in which a triangular or trapezoidal-shaped access cavity is prepared to confine only the root canal orifices. As a CAC has a shorter margin than a traditional access opening, the size of the access cavity would be smaller than the traditional straight-line open access cavity. This conservative approach minimizes tooth structure loss, hence, might improve the fracture strength of endodontically treated teeth. ${ }^{11}$

Various access cavity preparation designs such as conventional access cavity design, ninja access cavity design, truss access cavity design, and ultra-CAC design have been studied and compared lately. ${ }^{10}$ However, the majority of these studies have been limited to permanent dentition only. Thus, there is a need to investigate the modifications in access cavity designs of primary molars that possess dual abilities of complete debridement of root canals as well as adhering with the conservation of sound tooth structure to eliminate the need for full coverage restorations postendodontically in primary molars. Therefore, the present study was planned to evaluate the efficacy of root canal debridement and fracture strength assessment of different shapes of access cavity preparation in primary mandibular molars.

\section{Materials and Methods}

Sixty extracted human primary mandibular molars with at least two-third of roots remaining were selected for the study and called samples. Primary molars with grossly mutilated crown, less than two-thirds of roots, and those with internal resorption were excluded from the study. The selected teeth were stored in $10 \%$ formalin until used.

\section{Division of Samples}

The samples were randomly and equally divided into the following two groups, depending upon the shape of the access cavity preparation, group I-TAC design and group II-CAC design. Each group was further subdivided into two subgroups 1 and $2, I_{1}, I_{2}$ and $I I_{1}, I_{2}$ with 15 samples each. Samples in subgroup 1 of each group were assigned for the evaluation of the efficacy of root canal debridement and those in subgroup 2 were assessed for fracture strength.

\section{Traditional Access Cavity}

Access cavity was prepared using round diamond bur directed perpendicular to the occlusal table, followed by enlarging the size of access cavity using non-end cutting Endo-Z bur. An initial outline of the access cavity was prepared parallel to the external surface of the tooth, leaving approx. $2 \mathrm{~mm}$ margins. ${ }^{12}$

\section{Conservative Access Cavity}

The shape of the access cavity was encoded to the number of canals. ${ }^{4}$ Triangular-shaped access cavity was prepared in samples with three root canals (mesiobuccal, mesiolingual, and distal); whereas the access cavity was prepared as trapezoidal if the extra canal was found (mesiobuccal, mesiolingual, distobuccal, and distolingual canal). ${ }^{4}$ The access cavity was prepared such that, it enclosed only the root canals.

\section{Root Canal Preparation}

All root canal instrumentation procedures were performed by a single operator. After deroofing the pulp chamber, the coronal pulp was removed using $3 \%$ sodium hypochlorite $(\mathrm{NaOCl})$ solution, followed by identification of root canal orifices using DG-16 endodontic explorer. Following working length determination, chemo-mechanical preparation of root canals was done using successively up to \#30 K-file in a step back fashion along with copious irrigation with $0.9 \%$ normal saline solution, $3 \%$ sodium hypochlorite followed by irrigation with saline, 17\% EDTA, and saline again. The canals were dried using absorbent paper points.

\section{Histological Evaluation for Assessment of Root Canal Debridement}

The specimen in group $\mathrm{I}_{1}, \mathrm{II}_{1}$ were processed for histologic examination. Specimen were fixed in $10 \%$ neutral buffered formalin for 48 hours, washed in water, and decalcified in a $100 \mathrm{~mL}$ solution of formic acid-formalin solution, for 1 week. The specimen was rinsed with water and dehydrated, followed by washing the teeth in tap water. The teeth were sectioned horizontally to achieve 4 $\mu \mathrm{m}$ thick sections at the cervical third or middle third of the root canal and processed. The sections were mounted on the glass slide and stained with hematoxylin-eosin stain. Five sections were chosen from each area of interest for each tooth and visualized using Olympus binocular microscope with a digital camera at $4 x$ magnification. Captured images were analyzed for any remnant pulp tissue or debris, using a scale ranging from 0 to 4 , criteria adopted by Siqueira et al. ${ }^{13}$ (Table 1 ).

\section{Fracture Strength Assessment}

Following root canal preparation, samples in group $\mathrm{I}_{2}$ and $\mathrm{II}_{2}$ were obturated using calcium hydroxide paste (metapex) and restored with bonded composite resin. Samples were mounted into the selfcure acrylic resin, such that the roots of the molars are embedded in the acrylic resin till $2 \mathrm{~mm}$ short of CEJ. The prepared samples were evaluated for fracture strength by loading under the Instron Universal Testing Machine. The continuous compressive force was applied using ball ended compressive head at an inclination of $30^{\circ}$ to the long axis of the tooth and at the speed of $0.5 \mathrm{~mm} /$ minute. Force was applied until fracture occurred and the values were recorded in Newtons (N).

\section{Observations and Results}

All the data obtained for root canal debridement and fracture strength assessment were calculated, compared, and statistically analyzed using SPSS version 22.0 software. The level of significance

\begin{tabular}{ll} 
Table 1: & Scoring criteria to analyze remaining pulp or debris \\
\hline Score & Inference \\
\hline 0 & Debris and pulpal remnants seen on all 4 walls \\
1 & Debris and pulpal remnants seen on 3 walls \\
2 & Debris and pulpal remnants seen on 2 walls \\
3 & Debris and pulpal remnants seen on 1 wall \\
4 & No debris or pulpal remnants seen \\
\hline
\end{tabular}


was kept at $5 \%$. Comparison of fracture strength among the study groups was done using a one-way ANOVA test followed by a post hoc Tukey test for pairwise comparison. Comparison of canal debridement scores among the study groups was done using the Kruskal-Wallis test followed by Mann-Whitney test for pairwise comparison.

\section{Root Canal Debridement Assessment}

The H\&E-stained microscopic images at $4 \times$ magnification (Fig. 1) were captured and analyzed using the scoring criteria adopted by Siqueira et al. ${ }^{13}$

The mean values of assessment of root canal debridement in mesial and distal roots among the two groups showed that the mean value for root canal debridement in mesial root was 3.20 and for distal root was 3.13 , in group $\mathrm{I}_{1}$ (TAC). In group $\mathrm{I}_{2}$ (CAC), the mean values for root canal debridement in mesial and distal root were 2.27 and 2.40 , respectively (Table 2 ). The mean value scores were found to be highest for group $\mathrm{I}_{1}$ (TAC), indicating better debridement of root canals compared to that prepared through group $I_{1}$ (CAC) (Fig. 2).

Intergroup comparisons between both the groups showed statistically significant difference ( $p$ value $\leq 0.05$ ) in root canal debridement scores of mesial and distal roots (Table 3 and Fig. 3). This implies that TAC ( $g r o u p I_{1}$ ) could remove pulp and debris from the root canals of the primary mandibular molars more efficiently than CAC (group $\mathrm{II}_{1}$ ) preparation.

\section{Fracture Strength Assessment}

Fracture strength assessment values of two different shapes of access cavity preparation in extracted human mandibular primary molars depicted that mean compressive force was higher for group $I_{2}(C A C)$, compared with that of group $\mathrm{I}_{2}$ (TAC) (Table 4).

On intergroup comparison between the fracture strength among the two groups (Table 5), a highly statistically significant difference ( $p$ value $\leq 0.001$ ) was obtained in the mean compressive strength of group $\mathrm{I}_{2}$ and $\mathrm{II}_{2}$, with the mean difference of $92.80 \mathrm{~N}$ and 330.78 , respectively. As per the inference, it can be said that tooth samples prepared with CAC had the highest fracture strength because of the preservation of original tooth structure during endodontic access opening when compared with that of TAC (Fig. 4).

\section{Discussion}

Access cavity preparation is the first and arguably the most important step in endodontic therapy. ${ }^{14}$ Adequately prepared access cavity design facilitates unobstructed straight-line access to the root canal apex for complete debridement of the pulp from the root canals. ${ }^{15}$ Among the extensive literature on pulpectomy

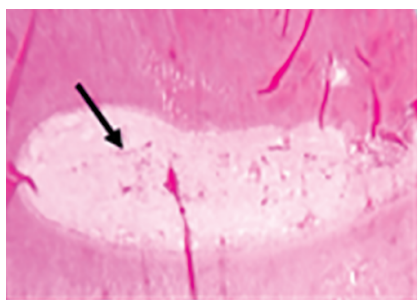

Score 0-debris and pulpal remnants seen on all 4 walls

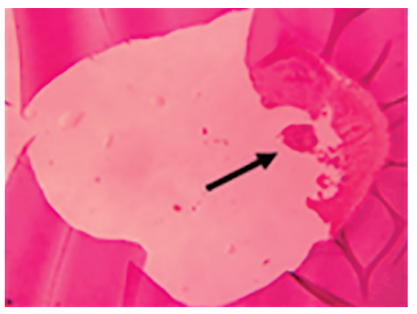

Score 0-debris and pulpal remnants seen on 1 wall
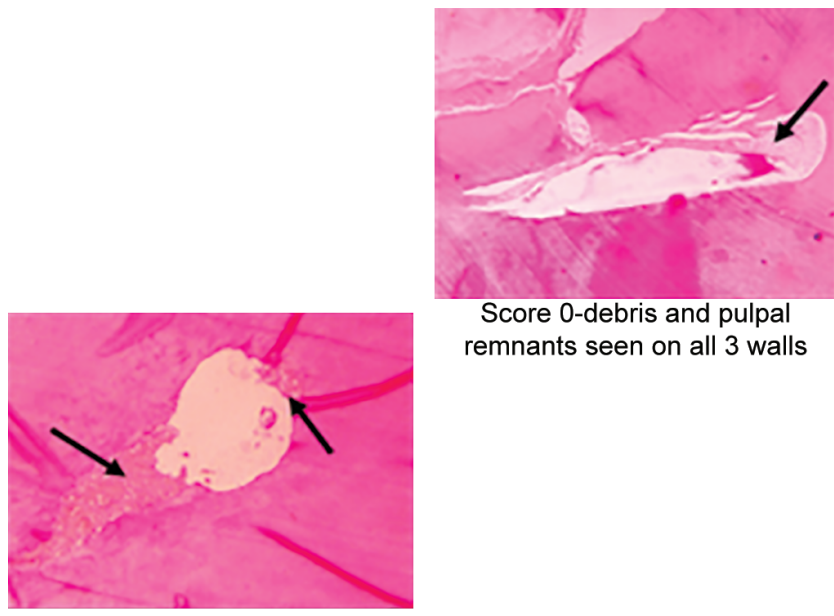

Score 0 -debris and pulpal remnants seen on all 2 walls

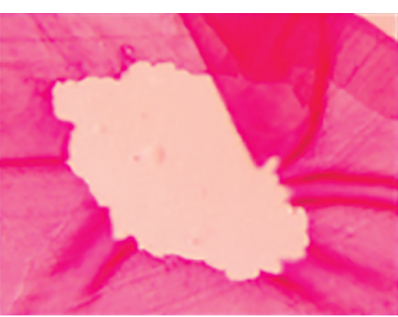

Score 0-no debris and pulpal remnants seen at all

Fig. 1: H\&E-stained microscopic images at $4 \times$ magnification and scoring criteria for assessment of root canal debridement

Table 2: Comparison of assessment of root canal debridement in mesial and distal root between the two groups

\begin{tabular}{llllllllll}
\hline Groups & & Score 0 & Score 1 & Score 2 & Score 3 & Score 4 & Mean values & $X^{2}$ values & $p$ value \\
\hline $\mathrm{I}_{1}(\mathrm{TAC})$ & Mesial root & $00(0 \%)$ & $00(0 \%)$ & $03(20 \%)$ & $07(46.6 \%)$ & $05(33.3 \%)$ & 3.20 & 15.560 & $0.001^{*}$ \\
& Distal root & $00(0 \%)$ & $00(0 \%)$ & $04(26.6 \%)$ & $07(46.6 \%)$ & $04(26.6 \%)$ & 3.13 & 9.599 & $0.008^{*}$ \\
\multirow{3}{*}{$\mathrm{II}_{1}(\mathrm{CAC})$} & Mesial root & $01(6.7 \%)$ & $02(13.3 \%)$ & $04(26.7 \%)$ & $08(53.3 \%)$ & $00(0 \%)$ & 2.27 & 15.560 & $0.001^{*}$ \\
& Distal root & $00(0 \%)$ & $01(6.6 \%)$ & $08(53.3 \%)$ & $05(33.3 \%)$ & $01(6.6 \%)$ & 2.40 & 9.599 & $0.008^{*}$ \\
\hline
\end{tabular}

${ }^{*} p$ value $\leq 0.001$, high statistically significant difference 

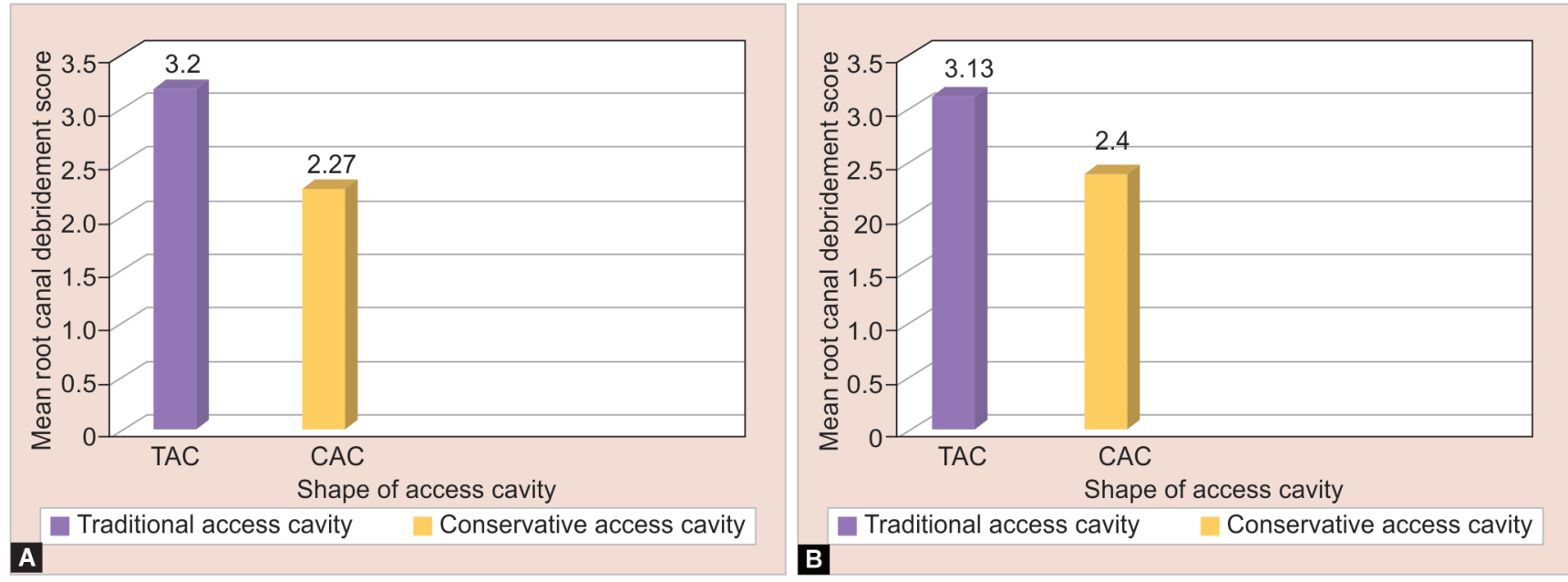

Figs 2A and B: Comparison of root canal debridement scores in mesial and distal roots between the two groups

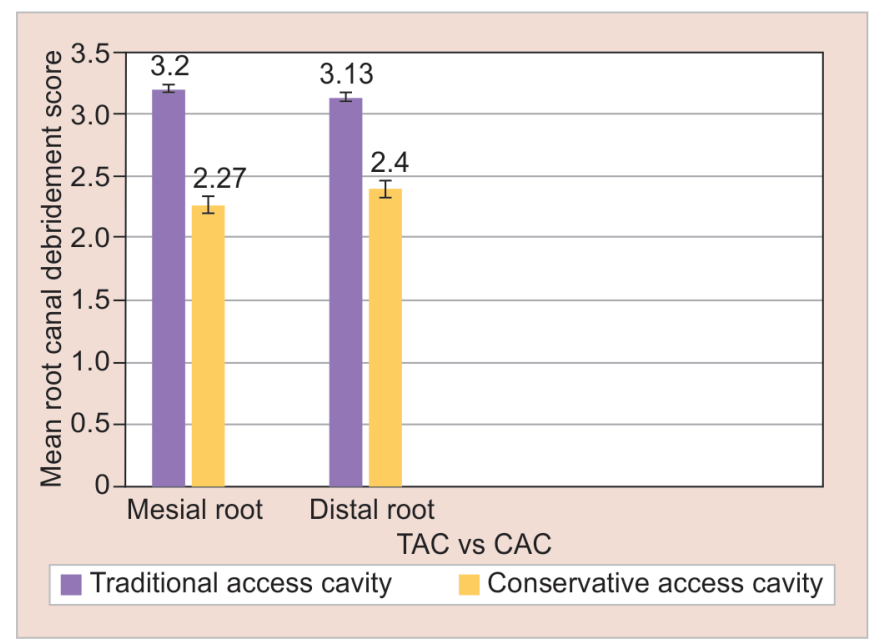

Fig. 3: Intergroup comparison of root canal debridement scores in mesial and distal roots between the two groups

Table 3: Intergroup comparison of assessment of root canal debridement in mesial and distal root between the two groups

\begin{tabular}{llll}
\hline Group $-I_{1}$ vs $I_{1}$ & Mean difference & $Z$ value & $p$ value \\
\hline Mesial root & 0.93 & -2.589 & $0.010^{*}$ \\
Distal root & 0.73 & -2.454 & $0.014^{*}$ \\
\hline
\end{tabular}

${ }^{*} p$ value $<0.05$, statistically significant difference

Table 4: Intergroup comparison of assessment of root canal debridement in mesial and distal root between the two groups

\begin{tabular}{lll}
\hline & $\begin{array}{l}\text { Mean compressive } \\
\text { Groups }\end{array}$ & Standard deviation \\
\hline $\mathrm{I}_{2}$ (TAC) & 247.61 & 46.58 \\
$\mathrm{I}_{2}$ (CAC) & 339.69 & 76.38 \\
\hline
\end{tabular}

Table 5: Intergroup comparison of fracture strength between the two groups

\begin{tabular}{lll}
\hline $\begin{array}{l}\text { Intergroup } \\
\text { comparison }\end{array}$ & Mean difference & $p$ value \\
\hline $\mathrm{I}_{2}$ vs $\mathrm{I}_{2}$ & -92.08 & $0.001^{*}$ \\
\hline${ }^{*} p$ value $\leq 0.05$, high statistically significant difference
\end{tabular}

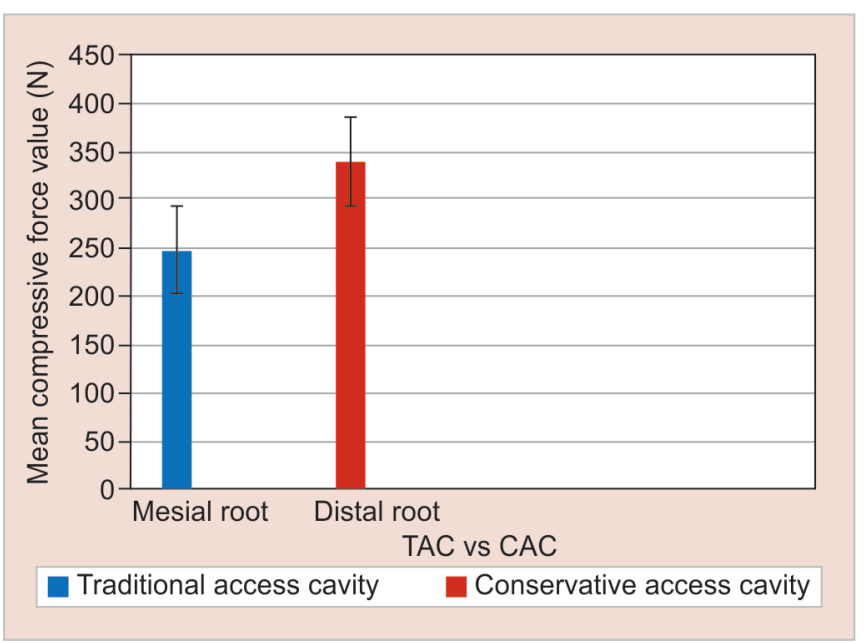

Fig. 4: Intergroup comparison of fracture strength between the two groups

in primary teeth, no specific shape, size, or design of the access cavity has been defined until now. Therefore, the present study was undertaken to evaluate the efficacy of root canal instrumentation for proper debridement and fracture strength assessment of different shapes of access cavity preparation namely, TAC, CAC. Endodontic treatment in primary molars is complicated due to complex root canal anatomy, the tortuous nature of canals, and continually occurring morphological changes. The classic endodontic access cavity (TAC) in primary molars is parallel to the external outline of the crown, leaving $2 \mathrm{~mm}$ of the crown margins. ${ }^{12}$ However, this extended access cavity critically reduces the amount of sound dentin and undermines the strength of the tooth to fracture under functional loads, ${ }^{7}$ which necessitates the use of full coverage restorations after endodontic therapy in primary molars. In the present study, the CAC design is dictated by the number of root canal orifices. ${ }^{4}$ In permanent mandibular first molar, the shape of the access cavity preparation is typically trapezoidal or rhomboidal, regardless of the number of canals present whereas, in a permanent mandibular second molar, the access cavity is more triangular and less rhombus. These triangular or trapezoidal shapes of CAC preparation in primary mandibular molars were attributed 
to the internal anatomy of the pulp chamber and number of canals, i.e., triangular shape for three canals and trapezoidal shape four or more canals. ${ }^{4}$ In primary mandibular first molar and second molar, it has been reported that approximately $75 \%$ and $85 \%$ of the mesial roots contain two canals, respectively, whereas only $25 \%$ of the distal root contains more than one canal in both the teeth. ${ }^{16,17}$ As the extension of the margins of the CAC was less than that of the traditional access opening, the size of the access cavity had been smaller than the straight-line open access cavity. Thus, the conservative approach has reduced the loss of tooth structure, and improved the fracture strength of endodontically treated teeth. Although CAC preparation preserves more dental hard tissue, it may be challenging to locate, debride, and disinfect all the root canals with such an approach. ${ }^{18}$

In the present study, TAC showed significantly better $(p>$ 0.05) root canal debridement efficacy compared to that of CAC in both mesial and distal roots of primary mandibular molars. Our findings were confluent with the similar study conducted by Krishan et al., in which traditional straight-line access cavity preparation showed excellent root canal debridement efficacy in permanent molars when compared with other CAC designs. ${ }^{19}$ A similar study was conducted by Neelakantan et al., who found that the amount of remaining pulp tissue was significantly less in root canals of extracted permanent mandibular molars, prepared through TAC preparation compared with that of orifice directed dentin conservation access cavity design (DDC). ${ }^{20}$ The better root canal debridement efficacy through TAC design could be attributed to the large size of the cavity, which ultimately facilitates direct visualization and location of the dentinal map and all the root canal orifices on the pulpal floor. The findings of the present study are in contrast to the results of a similar in vitro study conducted by Rover et al. and Moore et al. on permanent teeth, which showed that the percentage of non-debrided root canal area was unaffected by the access cavity design. ${ }^{18,21}$ One of the predominant causes of failure of root canal treatment in primary molars is the variation in root canal anatomy. ${ }^{22}$ In the present study, mean root canal debridement scores of distal roots were less in comparison to that of the mesial root, because the distal canals of primary mandibular molars are flat-oval, predominantly wider buccolingually, narrower mesiodistally, and typically ribbon shaped, ${ }^{23}$ which comprises the root canal debridement, especially in the apical regions. ${ }^{24}$ Thus, knowledge of the anatomical configuration of the canals is important, to avoid inadequate cleaning and shaping, leaving untouched fins on the buccal and/or lingual aspects of the canals. Various newer flexible instruments, high-level magnification devices such as direct operating microscopes, 3-dimensional scanners, or CBCT have been devised to overcome the procedural errors associated with visualization, location of root canal orifices, and instrumentation of root canals. ${ }^{25}$ However, CBCT imaging is not clinically applicable for children for routine procedures like pulpectomy due to high treatment cost, unnecessitated radiation exposure for the children, difficult patient cooperation, and limited availability of advanced technology like CBCT and direct operating microscopes. ${ }^{26,27}$ The introduction of nickeltitanium rotary file systems has resulted in marked progress in the mechanical preparation of the root canal space. ${ }^{28}$ However, in the present study, chemo-mechanical preparation was done using manual K-files and $\mathrm{H}$-files from ISO \#6 up to ISO \#30, corroborated with the findings of Versiani et al., which stated that large tapered rotary files should be avoided in primary mandibular molars considering their internal anatomical configuration. ${ }^{24,29}$ For the means of standardization, each instrument was used in one tooth. Various studies have suggested that the histologic approach is a widely accepted method to study the efficacy of root canal debridement and irrigation strategies. ${ }^{3,30,31}$ Removal of pulp tissue and microbial biomass from the root canal system appears to be related to the presence of extra canals or missed canals and accessibilities of irrigating solutions to anatomic eccentricities, in addition to volume, time, activation, and concentration of the irrigant used in the root canals. ${ }^{32}$ In the present study, remaining debris or pulp tissue was assessed using a scale ranging from 0 to 4 which was adopted from the studies conducted by Langeland et al. and Siqueria et al. for evaluation of remaining pulp..$^{13,33}$

For assessment of fracture strength, the samples were mounted on an Instron testing machine at a $30^{\circ}$ inclination angle, because the teeth are considered most vulnerable to fracture under eccentric forces. ${ }^{34}$ However, a similar methodology for assessment of fracture strength has been used in various in vitro studies but, it does not accurately simulate the intraoral conditions, in which failure occurs primarily because of fatigue. ${ }^{11}$ In the present study, the prepared access cavities were restored with bonded resin composite. Restoration of endodontically treated teeth may increase its fracture strength up to $72 \%$ of the mean fracture strength of intact teeth as suggested by Hamouda and Shehata. ${ }^{35}$ The results revealed that the fracture strength of CAC was significantly higher $(p<0.05)$ than that of the TAC design. This can be attributed to the small size of the access cavity or the amount of loss of tooth structure which is indirectly proportional to the fracture resistance of an endodontically treated tooth. Previous investigators have concluded that loss of tooth substance has reduced the fracture strength of the tooth due to caries and cavity preparation in endodontically treated teeth with extensive restorations. ${ }^{35,36}$ Makati et al. stated that the remaining dentin thickness was more in CAC when compared with TAC in permanent molars. ${ }^{37}$ Yuan et al. observed that the teeth with $C A C$ had significantly reduced stress in occlusal and cervical regions when compared with that of TAC designs. ${ }^{38}$ Lin et al. compared straight-line access cavity design with minimally invasive access cavity designs on 3-dimensional reconstruction models and concluded that remaining dentin thickness in TAC design was lowest amongst all the designs. ${ }^{39}$ The results of these studies were similar to the results of the present study, attributed to the wider TAC preparation, significant loss of sound tooth structure, and lowest fracture resistance of samples prepared through TAC compared with that of CAC preparation.

Both medicine and dentistry have observed a paradigm shift from more extensive to minimally invasive treatment modalities to maximize the comfort and benefits to the patients. CACs are more convenient for the patients, but it summons the clinicians to locate all canals, debride all the pulp tissue and debris, and avoid any procedural complications. Recent technological advancements in armamentariums such as CBCT imaging, operating microscopes, and nickel-titanium instruments could help clinicians in working effectively within confined spaces.

\section{ConCLUSION}

Based on the results of the present study the following conclusions were drawn: 
- Both the shapes of the access cavity preparation were able to debride the pulpal remnants and debris to the large extent in the mesial and distal roots of primary mandibular molars.

- Statistically significant differences were observed in the root canal debridement efficacy, after making different shapes of access cavity in primary molars. Traditional access cavity facilitated complete debridement of root canals of both the roots while CAC resulted in partial debridement of root canals. CAC was found to be least efficacious in debriding the pulp and debris from the root canals of primary mandibular molars.

- In terms of fracture strength, CAC showed higher fracture strength and required maximum compressive force to fracture the tooth under load, compared with that of TAC.

Within the limitations of this study, it can be concluded that TAC helps in complete debridement of root canals following instrumentation but results in weakening of tooth structure which necessitates the use of full coverage restoration after endodontic therapy. However, further studies with a larger sample size are required to be calculated to validate the results of the present study.

\section{ACKNOWLedgments}

I would like to acknowledge Dr Tushar Pruthi, Assistant Professor, and Dr Navpreet Kaur, Assistant Professor, Subharti Dental College and Hospital, Meerut for their valuable guidance and motivation during the progress of this original research.

\section{References}

1. Ahmed HM. Pulpectomy procedures in primary molar teeth. Eur J Dent 2014;3(1):3-6. DOI: 10.4103/2278-9626.126201.

2. Coll JA, Sadrian R. Predicting pulpectomy success and its relationship to exfoliation and succedaneous dentition. Pediatr Dent 1996;18(1):57-63.

3. Asundi A, Kishen A. Advanced digital photoelastic investigations on the tooth-bone interface. J Biomed Opt 2001;6(1):224-230. DOI: 10.1117/1.1344587.

4. Hargreaves KM, Berman LH. Cohen's pathways of pulp. 11th ed., U.S.A: Elsevier; 2016.

5. Dean JA, Jones JE, Vinson LW. McDonald and Avery's dentistry for the child and adolescent. U.S.A: Elsevier; 2016.

6. Sabeti M, Kazem M, Dianat $O$, et al. Impact of access cavity design and root canal taper on fracture resistance of endodontically treated teeth: an ex vivo investigation. J Endod 2018;44(9):1402-1406. DOI: 10.1016/j.joen.2018.05.006.

7. Monga P, Sharma V, Kumar S. Comparison of fracture resistance of endodontically treated teeth using different coronal restorative materials: an in vitro study. J Conserv Dent 2009;12(4):154-158. DOI: 10.4103/0972-0707.58338.

8. Rezaei DM, Amirian CK, Tavanafar S. Upper central incisors restored with different posts and cores. Restor Dent Endod 2015;40(3):229-235. DOI: 10.5395/rde.2015.40.3.229.

9. Auswin MK, Ramesh S. Truss access new conservative approach on access opening of a lower molar: A case report. J Adv Pharm 2017;7(3):134-136.

10. Belladonna FG, De-Deus G, Dummer PM, et al. Current status on minimal access cavity preparations: a critical analysis and a proposal for a universal nomenclature. Int Endod J 2020;53(12):1618-1635. DOI: 10.1111/iej.13391.

11. Plotino G, Grande NM, Isufi A, et al. Fracture strength of endodontically treated teeth with different access cavity designs. J Endod 2017;43(6):995-1000. DOI: 10.1016/j.joen.2017.01.022.
12. Cheong J, Chiam S, King NM, et al. Pulp chamber analysis of primary molars using micro-computed tomography: Preliminary findings. J Clin Pediatr Dent 2019;43(6):382-387. DOI: 10.17796/1053-4625-43.6.4

13. Siqueira JF, Araújo MCP, Garcia PF, et al. Histological evaluation of the effectiveness of five instrumentation techniques for cleaning the apical third of root canals. J Endod 1997;23(1):499-502. DOI: 10.1016/ S0099-2399(97)80309-3.

14. Adams N, Tomson PL. Access cavity preparation. Br Dent J. 2014;216(6):333-339. DOI: 10.1038/sj.bdj.2014.206.

15. McCabe PS. Avoiding perforations in endodontics. J Ir Dent Assoc 2006;52(3):139-148.

16. Hibbaed ED. Morphology of the root canals of the primary molar teeth. J Dent Child 1957;24(3):250-257.

17. Zurcher E. The anatomy of the root canals of the teeth of the deciduous dentition and of the first permanent molars. New York: William Woods \& Co.; 1925.

18. Rover G, Belladonna FG, Bortoluzzi EA, et al. Influence of access cavity design on root canal detection, instrumentation efficacy, and fracture resistance assessed in maxillary molars. J Endod 2017;43(10):16571662. DOI: 10.1016/j.joen.2017.05.006.

19. Krishan R, Paqué $F$, Ossareh $A$, et al. Impacts of conservative endodontic cavity on root canal instrumentation efficacy and resistance to fracture assessed in incisors, premolars, and molars. J Endod 2014;40(8):1160-1166. DOI: 10.1016/j.joen.2013.12.012.

20. Neelakantan P, Khan K, Ng GP, et al. Does the orifice-directed dentin conservation access design debride pulp chamber and mesial root canal systems of mandibular molars similar to a traditional access design. J Endod 2018;44(2):274-279. DOI: 10.1016/j.joen.2017. 10.010 .

21. Moore B, Verdelis K, Kishen A, et al. Impacts of contracted endodontic cavities on instrumentation efficacy and biomechanical responses in maxillary molars. J Endod 2016;42(12):1779-1783. DOI: 10.1016/j. joen.2016.08.028.

22. Katge F, Wakpanjar MM. Root canal morphology of primary molars by clearing technique: an in vitro study. J Indian Soc Pedod Prev Dent 2018;36(2):151-155. DOI: 10.4103/JISPPD.JISPPD_237_16.

23. Fumes AC, Sousa-Neto MD, Leoni GB, et al. Root canal morphology of primary molars: a micro-computed tomography study. Eur Arch Paediatr Dent 2014;15(5):317-326. DOI: 10.1007/s40368-014-0117-0.

24. Paqué $F$, Balmer $M$, Attin $T$, et al. Preparation of oval-shaped root canals in mandibular molars using nickel-titanium rotary instruments: a micro-computed tomography study. J Endod 2010;36(2):703-707. DOI: 10.1016/j.joen.2009.12.020.

25. Alghnay M, Aljuieed $\mathrm{H}$. Conservative access cavity preparations. EC Dent Sci 2020;19(1):1-6.

26. Aps JK. Cone beam computed tomography in paediatric dentistry: overview of recent literature. Eur Arch Paediatr Dent 2013;14(3):131140. DOI: 10.1007/s40368-013-0029-4.

27. Horner K, Barry S, Dave M, et al. Diagnostic efficacy of cone beam computed tomography in paediatric dentistry: a systematic review. Eur Arch Paediatr Dent 2019;19(2):1-20. DOI: 10.1007/s40368-01900504-x.

28. Hülsmann M, Peters OA, Dummer PMH. Mechanical preparation of root canals: shaping goals, techniques and means. Endod Topics 2005;10(1):30-76. DOI: 10.1111/j.1601-1546.2005.00152.x.

29. Versiani MA, Pe'cora JD, Sousa-Neto MD. Flat-oval root canal preparation with self-adjusting file instrument: a micro-computed tomography study. J Endod 2011;37(4):1002-1007. DOI: 10.1016/j. joen.2011.03.017.

30. De-Deus G, Souza EM, Barino B. The self-adjusting file optimizes debridement quality in oval-shaped root canals. J Endod 2011;37(3):701-705. DOI: 10.1016/j.joen.2011.02.001.

31. Habib AA, Taha MI, Farah EM. Methodologies used in quality assessment of root canal preparation techniques: Review of the literature. J Taibah Univ Med Sci. 2015;10(2):123-131. DOI: 10.1016/j. jtumed.2014.11.002. 
32. Rodrigues RCV, Zandi H, Kristoffersen AK, et al. Influence of the apical preparation size and the irrigant type on bacterial reduction in root canal-treated teeth with apical periodontitis. J Endod 2017;43(7):1058-1063. DOI: 10.1016/j.joen.2017. 02.004 .

33. Langeland K, Liao K, Pascon EA. Work-saving devices in endodontics: efficacy of sonic and ultrasonic techniques. J Endod 1985;11(11):499510. DOI: 10.1016/s0099-2399(85)80223-5.

34. ElAyouti A, Serry MI, Geis-Gerstorfer J, et al. Influence of cusp coverage on the fracture resistance of premolars with endodontic access cavities. Int Endod J 2011;44(6):543-549. DOI: 10.1111/j.13652591.2011.01859.x.

35. Hamouda IM, Shehata SH. Fracture resistance of posterior teeth restored with modern restorative materials. J Biomed Res 2011;25(6):418-424. DOI: 10.1016/S1674-8301(11)60055-9.
36. Linn J, Messer HH. Effect of restorative procedures on the strength of endodontically treated molars. J Endod 1994;20(10):479-485. DOI: 10.1016/S0099-2399(06)80043-9.

37. Makati $D$, Shah NC, Brave $D$, et al. Evaluation of remaining dentin thickness and fracture resistance of conventional and conservative access and biomechanical preparation in molars using conebeam computed tomography: an in vitro study. J Conserv Dent 2018;21(3):324-328. DOI: 10.4103/JCD.JCD_311_17.

38. Yuan K, Niu C, Xie Q, et al. Comparative evaluation of the impact of minimally invasive preparation vs. conventional straight-line preparation on tooth biomechanics: a finite element analysis. Eur J Oral Sci 2016;124(8):591-596. DOI: 10.1111/eos.12303.

39. Lin CY, Lin D, He WH. Impacts of 3 different endodontic access cavity designs on dentin removal and point of entry in 3-dimensional digital models. J Endod 2020;46(4):524-530. DOI: 10.1016/j.joen.2020.01.002. 